\title{
DESENVOLVIMENTO DO PENSAMENTO E OPERAÇÕES RACIONAIS: CONTRIBUIÇÕES DA TEORIA HISTÓRICO-CULTURAL PARA A ORGANIZAÇÃO DO ENSINO DE MATEMÁTICA
}

\author{
DEVELOPMENT OF THOUGHT AND RATIONAL OPERATIONS: CONTRIBUTIONS OF \\ HISTORICAL-CULTURAL THEORY TO THE ORGANIZATION OF MATHEMATICS TEACHING
}

\author{
DESARROLLO DEL PENSAMIENTO Y OPERACIONES RACIONALES: CONTRIBUCIONES DE \\ LA TEORÍA HISTÓRICO-CULTURAL A LA ORGANIZACIÓN DE LA ENSEÑNANZA DE LA MATEMÁTICA
}

\author{
EDILSON DE ARAÚJO DOS SANTOS 1 \\ SILVIA PEREIRA GONZAGA DE MORAES²
}

\section{RESUMO}

Este trabalho é resultado de uma pesquisa de mestrado que objetivou investigar o as operações racionais de estudantes do terceiro ano de escolarização mediante a execução das tarefas escolares de matemática. A investigação teve como referência os pressupostos da Teoria Histórico-Cultural. Para isso, realizamos, em um primeiro momento, estudos bibliográficos sobre as operações racionais aqui compreendidas como os mecanismos internos do pensamento que medeiam os signos e símbolos. Em conjunto a esses estudos, desenvolvemos a pesquisa empírica, por meio de observações de aulas de matemática, em uma turma do $3^{\circ}$ ano do Ensino Fundamental de uma escola pública, localizada na região noroeste do Paraná. A sistematização dos dados foi feita por meio de episódios e cenas que se constituem em uma forma de expressarmos a unidade mínima de análise - a relação entre a organização do ensino e as operações racionais. Para este artigo trazemos o trabalho com o conceito de ordem e multiplicação.

Palavras-chave: Teoria Histórico-Cultural. Pensamento. Operações Racionais. Organização do Ensino de Matemática. Tarefas Escolares.

\section{ABSTRACT}

This work is the result of a master's research that aimed to investigate the rational operations of students in the third year of schooling through the execution of school math tasks. The investigation was based on the assumptions of Historical-Cultural Theory. To this end, we carried out, at first, bibliographic studies on the rational operations understood here as the internal mechanisms of thought that mediate signs and symbols. Together with these studies, we developed empirical research, through observations of mathematics classes, in a class of the 3rd year of elementary school in a public school, located in the northwest region of Paraná. The systematization of the data was done through episodes and scenes that constitute a way of expressing the minimum unit of analysis - the relationship between the organization of teaching and rational operations. For this article we bring the work with the concept of order and multiplication.

Keywords: Historical-Cultural Theory. Thought. Rational Operations. Organization of Mathematics Education. School Tasks.

\section{RESUMEN}

Este trabajo es el resultado de una investigación de maestría que tuvo como objetivo investigar el funcionamiento racional de los estudiantes en el tercer año de escolaridad a través de la ejecución de tareas escolares de matemáticas.

1 Mestre em Educação pela Universidade Estadual de Maringá (UEM).Professor na rede municipal de educação de Maringá. E-mail: ediegidiosantos@ gmail.com. Orcid: https://orcid.org/0000-0002-6430-0489

2 Doutora em Educação pela Universidade de São Paulo (USP). Professora no Programa de Pós-Graduação em Educação da Universidade Estadual de Maringá. E-mail: spgmoraes@uem.br. Orcid: https://orcid.org/0000-0003-0937-5581 
La investigación se basó en los supuestos de la Teoría Histórico-Cultural. Para ello, realizamos, en un primer momento, estudios bibliográficos sobre las operaciones racionales entendidas aquí como los mecanismos internos del pensamiento que median signos y símbolos. Junto a estos estudios, desarrollamos una investigación empírica, a través de observaciones de clases de matemáticas, en una clase de 3er año de Primaria en una escuela pública, ubicada en la región noroeste de Paraná. La sistematización de los datos se realizó a través de episodios y escenas que constituyen una forma de expresar la unidad mínima de análisis, la relación entre la organización de la enseñanza y las operaciones racionales. Para este artículo traemos el trabajo con el concepto de orden y multiplicación.

Palabras-clave: Teoría histórico-cultural. Pensamiento. Operaciones racionales. Organización de la enseñanza de la matemática. Tareas escolares.

\section{INTRODUÇÃO}

A complexidade da prática pedagógica envolvendo os conceitos matemáticos intensifica a pluralidade de debates e opiniões acerca de questões sobre: 0 que ensinar? Como ensinar? Para quem ensinar? Quando ensinar? Tais questões são mobilizadoras de pesquisas e debates na área de Educação, em especial, na Educação Matemática e trazem como pano de fundo a função social da escola. Moura e Araujo (2018) ao retratarem a função da escola, defendem que a educação escolar é condição para que os sujeitos se apropriem das ferramentas simbólicas necessárias para sua inserção e transformação da realidade em que vivem. Os autores defendem que a educação escolar, por sua tradição e tempo de existência, já tem, ou deveria ter, "[...] conhecimento acumulado para melhor organizar situações que potencializem 0 desenvolvimento das capacidades humanas para a apropriação da cultura e para o convívio social” (MOURA; ARAUJO, 2018, p. 193).

Desse modo, consideramos que a escola se configura em um espaço de ensino, no qual deve ocorrer a aprendizagem dos conceitos científicos das diferentes áreas de conhecimentos, com vistas ao desenvolvimento psíquico dos sujeitos.

Sforni (2016) descreve que, mesmo estando inseridos no espaço escolar, a aquisição de conhecimentos é muito distante em nível de apropriação para parte dos estudantes. A autora esclarece que "[...] isso não significa que na escola não se ensina" (SFORNI, 2016, p. 57). Assim, observamos que os conhecimentos estão no espaço escolar, porém

[...] não basta ao sujeito frequentar a escola e ter acesso a conceitos científicos para que se aproprie do nível de pensamento presente na produção científica e cultural da qual o conceito faz parte e, consequentemente, tenha seus processos internos de desenvolvimento acionados. Há que se ter acesso a uma situação de ensino adequadamente organizada[...] (SFORNI, 2016, p. 57, grifos nosso).

Destarte, colocamos em destaque para a análise as operações racionais dos estudantes, já que os escolares realizam diversas tarefas no decorrer de seu processo de escolarização (como já relatado por FERREIRA, 2017; ASSUMPÇÃO 2018; MORAES, VIGNOTO, 2013), entretanto, questionamos: As tarefas de matemática proporcionam o desenvolvimento qualitativo das operações racionais para a formação e aperfeiçoamento das funções psicológicas superiores, em especial, o pensamento?

Este texto busca expor parte dos dados referentes a uma pesquisa de mestrado que teve como objetivo investigar a formação das operações racionais por meio da análise das tarefas escolares de matemática, tendo em vista a relação ensino, aprendizagem e desenvolvimento do pensamento 
teórico (SANTOS, 2020). 0 espaço em que se manifesta o fenômeno da execução das tarefas ao qual abordamos nesta investigação é a escola. Consideramos que a compreensão do processo de formação das operações racionais no contexto de sala de aula pode contribuir para a organização de atividades de ensino potencializadoras da aprendizagem dos conceitos matemáticos e a formação do pensamento teórico.

Assim, ao delimitarmos nosso estudo para a compreensão do pensamento e as operações racionais na execução das tarefas escolares de matemática, partimos da premissa que apontaram Smirnov e Menchinskaia (1960), ao determinar que a atividade racional, portanto, as operações racionais se encontram em "[...] qualquer aspecto da atividade humana, pois desta é exigido a resolução de tarefas racionais" (SMIRNOV; MENCHINSKAIA, 1960, p. 234). Desse modo, mesmo que a instituição em que realizamos a investigação não adote os pressupostos da Teoria Histórico-Cultural para a organização da prática pedagógica, isto é, mesmo que não tenha explicitamente o objetivo de desenvolvimento do pensamento teórico, todas as tarefas que os estudantes realizam colocam em movimento suas operações racionais.

Para investigar o movimento das operações racionais realizamos observações nas aulas de matemática em um $3^{\circ}$ ano do Ensino Fundamental, a fim de identificarmos a direção que a organização do ensino influi no desenvolvimento do pensamento e das operações racionais, por meio da execução das tarefas escolares de matemática. Para compreendermos esse processo, as ações da docente e dos escolares foram registradas por meio de gravações de áudio e fotografias.

Por se tratar de uma investigação sobre a organização do ensino e tendo as tarefas escolares, também como fonte de análise, consideramos necessário explicitar o significado destas. De acordo com Assumpção (2018), as tarefas escolares representam os registros das ações do professor no processo didático constituído por intenções e concepções de ensino e, também, das ações do estudante, como sujeito no processo de aprendizagem. Desse modo, ao investigarmos a organização do ensino em meio a realização das tarefas escolares, teremos indícios sobre a qualidade do desenvolvimento psíquico destes sujeitos, destacando a formação do pensamento para o estudo.

Neste trabalho, realizamos uma síntese sobre a Teoria Histórico-Cultural e destacamos possíveis pontos de articulação que contribuem para a organização do ensino. Em seguida, discorremos sobre a concepção ensino de matemática que defendemos, isto é, um instrumento do homem para a humanidade. Tendo em conta estes pressupostos discutimos o pensamento e as operações racionais, pois, estas operações são responsáveis pela formação do pensamento como de todo 0 psiquismo, seja a nível empírico como teórico. Por fim, para exemplificar essa relação expomos um dos episódios sistematizados na dissertação.

\section{TEORIA HISTÓRICO-CULTURAL E EDUCAÇÃO ESCOLAR}

Qual a necessidade dos estudos em psicologia para as pesquisas em educação? Davídov (1988) descreve que as investigações realizadas por Vygotski ${ }^{3}$ conduziram ao exame das condições em que ocorrem os processos de Ensino e Educação. Encontramos em Rubinstein e Sokolov (1960) uma possível síntese que justifica as contribuições da Psicologia aos estudos sobre a organização do ensino:

As leis dos processos cognoscitivos (sensação percepção pensamento, imaginação e memória) servem de base científica ao ensino e permitem determinar o conteúdo do

3 Na literatura, a grafia do nome Vigotski é encontrada de diferentes formas. Neste trabalho empregamos a grafia Vygotski, mas preservamos, nas indicações bibliográficas, a grafia adotada em cada uma delas. 
material escolar necessário para assimilar conhecimento e hábitos. São também o fundamento dos métodos de ensino, da elaboração e aplicação dos métodos mais fecundos de explicação do material escolar e de sua memorização pelos alunos, assim como a aplicação dos conhecimentos adquiridos na prática. As leis da percepção, da memória e do pensamento devem ser tidas em conta ao escrever os livros didáticos e na elaboração do material escolar. (RUBISNTEIN; SOKOLOV, 1960, p. 24, grifos do autor)

Desse modo, a compreensão das leis do desenvolvimento das funções psicológicas superiores e suas particularidades devem fundamentar, também, a elaboração das tarefas escolares. De maneira semelhante, Vygotski (2000) aponta que, para a criação de métodos de ensino eficientes, é necessária a compreensão do desenvolvimento dos conceitos científicos pelos escolares, ou seja, o conhecimento sobre as leis do desenvolvimento na esfera psicológica fornece elementos para a organização do ensino. Com isso, constatamos que a pedagogia e a psicologia se articulam mesmo seus objetos de estudos sendo distintos. Sobre isso, Araujo e Moraes (2017, p. 51) afirmam que "[...] o objeto das pesquisas em Educação (a Atividade Pedagógica) apresenta-se como uma condição das pesquisas em Psicologia, do mesmo modo que o objeto das pesquisas em Psicologia (as leis do desenvolvimento do psiquismo humano) apresenta-se como condição das pesquisas em Educação".

Assim, consideramos que essas duas áreas do conhecimento têm diferentes objetos de investigação, porém se complementam a ponto de serem interdependentes. A relação ensino, aprendizagem e desenvolvimento constitui-se fundamental para a organização da atividade pedagógica, objeto da educação. Diante disso, buscamos nas pesquisas dos psicólogos soviéticos, os resultados de suas investigações sobre essa relação.

Vigotski (2000), em uma das suas investigações, traz como problema o desenvolvimento dos conceitos científicos em idade escolar e indaga: "[...] o que acontece na mente da criança com os conceitos científicos que lhe são ensinados na escola?" (VIGOTSKI, 2000, p. 103). Ao debruçar sobre essa questão, 0 autor discorre sobre a diferença e relações entre os conceitos espontâneos e conceitos científicos. Para Vigotski (2000), os conceitos espontâneos são formados na relação direta dos sujeitos na prática social, e os conceitos científicos necessitam do ensino sistematizado e intencional. Martins (2013), valendo-se dos estudos da Teoria Histórico-cultural e da Pedagogia Histórico-Crítica, afirma que essas abordagens compreendem que 0 desenvolvimento das capacidades especificamente humanas acontece por meio da apropriação da cultura humana objetivada.

Como condição de apropriação da cultura humana, encontramos em Vigotskii (1988, p. 115, grifos nossos) que "[...] a aprendizagem não é, em si mesma, desenvolvimento, mas uma correta organização da aprendizagem da criança conduz ao desenvolvimento mental [...]". Diversos pesquisadores, dentre eles Davýdov 4 (1999); Moura et al. (2010); Sforni (2004, 2015); Moraes (2008, 2009); Lacanallo (2011; 2018) entre outros, se debruçaram a fim de compreender o que viria a ser a correta organização do ensino. Ao tratar dos processos de aprendizagem e desenvolvimento, Vigotskii (1988) aponta-nos uma direção em que o trabalho educativo deve adiantar o desenvolvimento psíquico.

Para Vigotskii (1988) chegar a essas conclusões, estudou as concepções anteriores e, por superação, inseriu uma nova forma de compreender a relação entre aprendizagem e desenvolvimento. 0 autor indica que "[...] a aprendizagem da criança começa muito antes da aprendizagem escolar" (VIGOTSKII, 1988, p. 109) e se apoia nesse fato para descrever que a aprendizagem escolar nunca começa do zero. Nesse sentido, Vigotskii (1988) afirma que a aprendizagem conduz ao desenvolvimento.

4 Quando nos referimos ao autor, utilizaremos a grafia Davydov, todavia, ao nos referirmos a uma produção do autor, manteremos a grafia da obra original. 
Outro termo a ser destacado na produção científica de Vigotskii (1988) é o de zona de desenvolvimento próximo, que, de acordo com Chaiklin (2011), é um dos conceitos mais conhecidos dos estudos advindos da abordagem vygotskiana. Chaiklin (2011) afirma que o conceito de zona de desenvolvimento próximo foi abordado nos estudos de Vygotsky como um modelo explicativo do desenvolvimento infantil, segundo o qual, este: 1) deve ser explicativo, e não descritivo ao ter como base os princípios que explicam o desenvolvimento; 2) deve considerar a criança em uma totalidade, isto é, considerar a integralidade do sujeito; e 3) o modelo explicativo deve ser dividido em períodos com o conteúdo devendo ser as características e princípios destes.

Desse modo, Vigotskii (1988), ao realizar o estudo acerca do desenvolvimento infantil, aponta que existem dois níveis de desenvolvimento: 0 nível de desenvolvimento real e a zona de desenvolvimento próximo. 0 nível de desenvolvimento real corresponde às aquisições mentais já obtidas pela criança, em outras palavras, é aquilo que ela já consegue realizar sozinha. Na zona de desenvolvimento próximo, estão as possibilidades de aprendizagem da criança e essa equivale às tarefas as quais a criança não consegue realizar sozinha, necessitando de uma ação externa, direcionando-a. Vigotskii (1988) aponta que o trabalho educativo tem como função desenvolver nos escolares aquilo que thes falta, assim, o ensino deve atuar na zona de desenvolvimento próximo.

Diante dessas afirmações, retomamos a questão "o que vem a ser uma correta organização do ensino?", ensino este que, corretamente organizado, atue o desenvolvimento dos sujeitos e não sobre 0 que ele já domina. Constatamos em Vigotski (1991), que o ensino deve ser organizado com base nos conceitos científicos. 0 autor aponta que 0 aprendizado desses conceitos em idade escolar é "[...] uma poderosa forma que direciona 0 seu desenvolvimento, determinando 0 destino de todo seu desenvolvimento mental" (VIGOTSKY, 1991, p. 107).

Há entre os estudiosos da Teoria Histórico-Cultural (Davídov, 1982, 1988, 1999; Vigotski 1991) uma crítica sobre o ensino que não ultrapassa as barreiras dos conhecimentos espontâneos. Vigotski (1991) explica que o desenvolvimento dos conhecimentos espontâneos ocorre sem a necessidade de uma instituição de ensino, mas o mesmo não acontece com os conhecimentos científicos, estes necessitam de uma sistematização adequada para sua aprendizagem, pois "[...] fornecem as estruturas para 0 desenvolvimento ascendente dos conceitos espontâneos da criança em relação a consciência [...]" (VIGOTSKI, 1991, p. 136), ou seja, os conceitos científicos incorporam, por superação, os conhecimentos espontâneos.

Considerando que a correta organização do ensino decorre da apropriação dos conceitos científicos, o que estes conceitos devem desenvolver no intelecto dos escolares? Encontramos em Davídov (1982, p. 7), que se trata do pensamento teórico, este tipo de pensamento "[...] não surge e nem se desenvolve na vida cotidiana das pessoas, ele se desenvolve somente em uma tal instrução, cujos programas se baseiam na compreensão dialética do pensamento".

Neste tópico, discorremos sobre as possíveis articulações entre Psicologia e os estudos em Educação, no qual o ensino deve atuar como motor do desenvolvimento humano mediante a apropriação de conceitos científicos. Diante destes pressupostos, no próximo tópico explicitamos acerca da concepção de matemática que se trata de um conhecimento científico histórico-social cujo caráter abstrato deriva das sínteses desenvolvidas em busca de soluções para os problemas gerados no coletivo. 


\section{MATEMÁTICA COMO CONHECIMENTO DA E PARA HUMANIDADE}

Caraça (1951) afirma no prefácio da obra Conceitos Fundamentais da Matemática, que "[...] a Matemática possui problemas próprios, que não tem ligação imediata com os outros problemas da vida social. Mas não há dúvida também de que os seus fundamentos mergulham tanto como os de outro qualquer ramo da Ciência, na vida real; (CARAÇA, 1951, p. XIV)". Deparamo-nos, no cotidiano escolar, com afirmações semelhantes às descritas por Caraça (1951) de que a matemática é algo distante da realidade ou, em outros casos, muito abstrata.

Talizina (2001) também tece reflexões sobre as barreiras postas sobre 0 ensinar e 0 aprender matemática em razão do nível mais elevado de abstração desta em relação às demais disciplinas escolares. A autora afirma que a matemática é, com frequência, considerada uma das disciplinas mais difíceis no período de escolarização e que em parte essa afirmativa se justifica por seu caráter abstrato. Todavia, como descreve Moura (2011, p. 8), "aprender a linguagem matemática é mais além que aprender códigos e regras". 0 autor complementa que a matemática é um "[...] método de conhecer e transmitir o que conhece. [...] É se fazer humano" (MOURA, 2011, p. 8). Desse modo, constatamos que o conhecimento matemático é parte da cultura humana produzida historicamente, e que permite ao sujeito tornar-se humano.

Considerando esses pressupostos, neste tópico objetivamos discorrer sobre a matemática como produção e instrumento da humanidade, em que para sua apropriação é necessário um ensino adequadamente organizado, tal qual já apontou Vigotskii (1988) em seus estudos basilares da Teoria Histórico-Cultural. Talizina (2001) pontua que encaminhar o ensino de matemática com base nos pressupostos vigotskianos é tarefa complexa, pois o trabalho docente não se restringe a identificar os alunos mais aptos em matemática, mas garantir que todos aprendam no decorrer do processo de escolarização.

Ao direcionarmos a nossa investigação para o processo de apropriação dos conceitos matemáticos e desenvolvimento psíquico, consideramos necessário definir a matemática tal como a defendemos. Corroboramos com Moura (2007) que a matemática é um conhecimento elaborado pela humanidade ao longo de seu processo histórico. Este conhecimento advém de necessidades da própria humanidade, que exigiu do homem a aprendizagem de técnicas e 0 desenvolvimento de conceitos que criam condições para a compreensão dos fenômenos (MOURA, 2007). Assim, a matemática configura-se como um instrumento da cultura humana para 0 controle, pelos sujeitos, da variação das diferentes grandezas no mundo circundante.

Assim, defendemos que 0 ensino de matemática deve criar condições aos sujeitos para a apropriação dos conceitos desta ciência, com isso, é necessário romper com a lógica de que os conceitos matemáticos somente devem e podem ser compreendidos por gênios, como explicou Caraça (1951). Na mesma direção, Moura (2007, p. 48) destaca que os conhecimentos matemáticos são "[...] instrumentos que capacitam o homem para satisfazer a necessidade de relacionar-se para resolver problemas", com isso, seu caráter abstrato da realidade é resultado de análises e sínteses advindas da dinâmica contínua de respostas dadas aos problemas gerados no coletivo. Nas palavras do autor,

Na aventura humana rumo ao aprimoramento da vida, a linguagem matemática desenvolve-se e participa do desenvolvimento de ferramentas para atender à ampliação da capacidade humana para manter-se vivo e confortável. A matemática atende, 
assim, um objetivo coletivo. Ela não se desenvolve a partir de uma necessidade individual. A necessidade é do coletivo e o indivíduo apreende as novas sínteses geradas na solução do problema coletivo. (MOURA, 2007, p. 49)

Diante esses pressupostos teóricos, qual deve ser a direção do trabalho pedagógico com os conceitos matemáticos? Davídov (1982) postula a necessidade de que, desde os primeiros anos em que a criança esteja no espaço escolar, o ensino deve estar direcionado ao desenvolvimento do pensamento teórico. Assim, questionamos: como criar condições para que se forme o pensamento teórico nos estudantes? Nos estudos de Davídov (1982), encontramos dois indicadores que lançam luz ao que indagamos: a alteração da base que fundamenta a organização do ensino de matemática; e, para ensinar matemática, é necessário iniciar dos conceitos gerais e não dos casos particulares. Moraes (2008, p. 75) sintetiza essas afirmações do autor, pontuando que

[...] os programas para 0 ensino de matemática não devem ser organizados obedecendo à sequência cronológica da ciência matemática. Ao contrário, deverão abarcar a produção científica dessa área do saber e organizar seus programas de acordo com as teses gerais do conhecimento matemático, buscando um trabalho relacional com os diferentes conteúdos matemáticos.

Nesse sentido, na organização do ensino de matemática (quando se tem como objetivo a formação do pensamento teórico) é condição que sejam evidenciadas as teses gerais do conhecimento a ser ensinado. A matemática e as demais disciplinas escolares são fundamentais para o desenvolvimento humano. Assim, consideramos essencial o estudo das leis gerais da formação da consciência de modo que, ao refletirmos sobre a organização do ensino que estão permeadas pelas tarefas que os estudantes realizam, possamos ter condições de pensar a direção do ensino na relação com a aprendizagem, o desenvolvimento do pensamento e as operações racionais. Adiante, no próximo tópico apresentamos ao leitor nosso delineamento metodológico para a pesquisa.

\section{DELINEAMENTO METODOLÓGICO}

Neste tópico, aproximamos o leitor do instrumento pelo qual capturamos os dados empíricos e 0 método de exposição do fenômeno, que são operações racionais de estudantes do terceiro ano de escolarização mediante a execução das tarefas escolares de matemática. Elegemos, como instrumento de investigação a observação dos estudantes no processo de realização das tarefas escolares em sala de aula. Araujo e Moraes (2017, p. 62) afirmam que esse momento da pesquisa deve estar direcionado para a apreensão da realidade, pois [...] refere-se fundamentalmente à ação de revelar 0 fenômeno em seu próprio processo de desenvolvimento, condição fundamental para determinar os aspectos essenciais do fenômeno em questão.

Rubinstein e Solokov (1960) corroboram ao defenderem que: observar as manifestações (ações de ensino e ações de estudo) dos indivíduos é indispensável para a investigação dos processos psíquicos, pois permite compreender o que dos estímulos (tarefas escolares) se torna objeto da consciência. Além da observação, os referidos autores explicitam a existência de outros instrumentos fundamentais na investigação psicológica: a experimentação, a conversação e os estudos dos produtos da atividade. Com base no que foi detalhado por Rubinstein e Solokov (1960), consideramos 
que esses instrumentos de captura podem ser empregados nas pesquisas em educação.Como mencionamos o instrumento de captura do fenômeno foi de observação, verificamos em Rubinstein e Sokolov (1960, p. 30) a existência de dois tipos de observação, a total e a selecionada. A primeira consiste no registro de "[...] todas as manifestações psíquicas em um tempo determinado (por exemplo: durante a execução de algum trabalho, durante uma aula ou um jogo)". A segunda, é quando 0 pesquisador objetiva somente registrar os dados referentes ao seu objeto, selecionando o que lhe é objeto de investigação.

Mesmo nos valendo dos cadernos dos escolares como fonte de pesquisa, nossa investigação tem por essência o instrumento de observação pelo qual o pesquisador acompanhou e registrou as manifestações dos estudantes no processo de realização das tarefas escolares.

A pesquisa sobre tarefas escolares tem sido um dos focos de estudo do Grupo de Pesquisa e Ensino "Trabalho Educativo e Escolarização" (GENTEE). Definimos como tarefas escolares a materialização das ações de ensino. Nos estudos de Moraes e Vignoto (2013), Locatelli (2015), Ferreira (2017) e Assumpção (2018), as tarefas escolares se configuram como a fonte de registro da Atividade Pedagógica, ou seja, manifestam as relações entre professores e alunos.

As tarefas escolares carregam (ou deveriam carregar) consigo os conteúdos das diferentes áreas de conhecimento, nelas estão implícitas suas intenções, há indicadores da prática pedagógica assumida, os conceitos abordados, de certa maneira, também indicam a concepção sobre o processo de apropriação do conhecimento e revela como ocorre a organização do ensino. (LOCATELLI, 2015, p. 12)

Os dados obtidos nesta investigação, oriundos da observação, remetem-se aos seguintes aspectos: às explicações feitas pela docente, ao modo de execução das tarefas em sala, às correções realizadas pela professora e estudantes, às tarefas executadas no livro didático, ao contexto em que foram solucionadas, às discussões sobre os conteúdos, às inferências feitas pelos escolares, ao tempo dedicado a cada tarefa, às ações da docente para a execução das tarefas, pois o registro no caderno pode ser apenas uma cópia, como também pode conter diferentes ações de ensino até que se chegue à cópia ou registro pelo próprio aluno. Constatamos que a observação in locus possibilitou-nos o contato com diferentes formas de abordar a temática das operações racionais.

Como expor o fenômeno investigado? Caraça (1951, p. 112, grifos do autor) afirma que, na inviabilidade de abarcar a totalidade do universo, o pesquisador "[...] recorta, destaca dessa totalidade, um conjunto de seres e fatos, abstraindo de todos os outros que com eles estão relacionados". 0 referido autor nomeia esses conjuntos de isolados. Assim, com base em Caraça (1951, p. 112), definimos por isolado uma parte da realidade, devendo "[...] compreender nele todos os fatores dominantes, isto é, todos aqueles cuja ação de independência influi no fenômeno a estudar". Araújo e Moraes (2017) afirmam que o conceito de isolado em Caraça se aproxima ao conceito de unidade mínima de análise, descrito por Vigotski. Nesta investigação utilizaremos a expressão unidade mínima de análise para nos referirmos ao isolado da pesquisa.

Reconhecemos como conteúdo da unidade mínima de análise a relação entre a organização do ensino e as operações racionais, manifestadas na atividade de ensino e atividade dos sujeitos em aprendizagem; esses conceitos são sistematizamos por Moura et al. (2010) com base nos estudos da Teoria Histórico-Cultural e da Teoria da Atividade.A atividade de ensino diz respeito aos modos e processos de organização do ensino, e a atividade de aprendizagem configura-se como a execução, por parte do aluno, das tarefas escolares. Esses conceitos estão alicerçados, como afirma Moraes $(2008,2009)$, na base teórico-metodológica para a organização do ensino, nomeada por Moura et al. (2010) como Atividade Orientadora de Ensino (AOE). 
0 que garante a unidade da Atividade Pedagógica é a interdependência entre a atividade de ensino e a atividade de aprendizagem compreendidas como 0 objeto das pesquisas em Educação. Portanto, a unidade mínima de análise da nossa investigação é a organização do ensino de matemática e as operações racionais.

As determinações da Atividade Pedagógica como 0 objeto geral das pesquisas em Educação e do pesquisador com esse objeto não se contrapõem ao fato de que esse objeto, em sua dimensão particular, constitui-se como tal apenas ao longo de uma investigação concreta. Do mesmo modo que os objetivos de uma pesquisa vão sendo mais bem precisados no desenvolvimento da própria pesquisa em questão, 0 objeto particular de uma investigação vai se desvelando no curso da própria investigação. (ARAUJO; MORAES, 2017, p. 57)

Para exemplificação desse percurso, o geral ponto de partida - atividade pedagógica, nessa pesquisa está na organização do ensino de matemática, expressa nas tarefas escolares. 0 objeto particular são as operações racionais dos estudantes no processo de execução das tarefas escolares de matemática. Porém diante de uma pesquisa em educação sustentada na Teoria Histórico-Cultural, essa particularidade é investigada tendo como ponto de partida a Atividade Pedagógica materializada na organização do ensino de matemática.

A exposição do conteúdo da unidade de análise, foi feita utilizando-se dos conceitos de episódios e das cenas que os compõem. Moraes (2008, p. 136, grifos da autora) afirma que os isolados/unidade de análise "[...] são compostos por episódios que são classes de fatos de explicitam empiricamente 0 fenômeno". A ideia de episódio é formulada por Moura (2000; 2004) ao investigar 0 processo formativo de professores. Para a escolha desses recursos metodológicos levou-se em consideração a possibilidade deles em revelar a relação entre as tarefas escolares, a organização do ensino e a mobilização das operações racionais dos estudantes do $3^{\circ}$ ano do Ensino Fundamental. Nessa direção, no próximo tópico apresentamos de modo sintético as operações racionais para 0 desenvolvimento das funções psíquicas, em especial o pensamento seja ele empírico ou teórico.

\title{
PENSAMENTO E OPERAÇÕES RACIONAIS
}

Neste tópico buscamos sistematizar a relação entre a formação do pensamento teórico e as operações racionais. Estas operações se inserem como estrutura que direciona 0 movimento do pensamento, e no processo de apropriação dos conceitos científicos temos a formação do pensamento teórico em um processo dialético, que vai do conhecido ao desconhecido. Ao afirmamos que o pensamento possui um movimento, não deixamos de reconhecer que deste derivam produtos, mas

\begin{abstract}
[...] 0 caráter específico do pensamento humano reside em que esse constitui uma interação não somente entre 0 homem pensante e a realidade percebida sensorialmente de maneira direta, mas, também, entre o homem e um sistema de conhecimentos socialmente elaborado e objetivado na palavra; é uma comunicação entre 0 homem e a humanidade. (RUBINSTEIN, 1974, p. 74)
\end{abstract}

Nesse sentido, destacamos 0 caráter socialmente condicionado do pensamento 0 qual se configura como o produto superior "[...] da matéria especificamente organizada - do cérebro -, é 0 
processo ativo do reflexo do mundo objetivo em conceitos, juízo, teorias etc." (PETROVSKI, 1980 p. 292). Desse modo,

A assimilação de conhecimento e o desenvolvimento do pensar é um processo dialético no qual a causa e o efeito mudam constantemente de lugar. Cada ato de assimilação de tais ou quais conhecimentos pressupõe, em qualidade de sua condição interna, o correspondente avanço do pensar, necessário para a assimilação de ditos conhecimentos; por sua vez, chega à criação de novas condições internas para poder assimilar conhecimentos. (RUBINSTEIN, 1974, p. 75)

Com isso, mediante 0 conhecimento do caráter socialmente condicionado do pensamento e das potencialidades que seu desenvolvimento implica no psiquismo dos sujeitos, verificamos a relevância dada à vida prática, ou seja, os processos perceptivos como base desta função psicológica superior. Rubinstein (1974) afirma que esse processo ocorre pelas operações racionais, dado que, em meio à complexificação das ações práticas, pode-se atingir o nível teórico, e, desse modo, 0 pensamento nunca deixará de ter suas bases nos processos perceptivos.

0 pensamento é, como afirmou Leontiev (1984, p. 30), uma função do cérebro humano, e esse pensar é um processo natural. Todavia, "[...] não existe a margem da sociedade, a margem dos conhecimentos acumulados pela humanidade e dos procedimentos da atividade pensante elaboradas por ela" (LEONTIEV, 1984, p. 30). 0 autor complementa que cada ser humano "[...] se converte em sujeito do pensamento somente quando domina a linguagem, os conceitos e a lógica, que constituem um reflexo generalizado da experiência da prática social: incluso aquelas tarefas que o homem reflete para seu pensamento são um produto das condições sociais de sua vida" (LEONTIEV, 1984, p. 32).

Davídov (1987) defende que a ênfase das ações escolares necessita ser em direção à formação do pensamento teórico, pois isso possibilita ao sujeito a formação de uma personalidade criativa e multilateral em que torna o sujeito capaz de articular sua capacidade produtiva às capacidades de pensar.

Assim, neste tópico, apresentamos as operações racionais e utilizamos como base para esta discussão os estudos de Shardakov (1977), Smirnov e Menchinskaia (1960), Rubinstein (1974, 1963), Davýdov (1982; 1988) e outros. A compreensão acerca de como é composta cada uma das operações racionais fornece elementos para a análise da organização do ensino mediante as tarefas realizadas pelos estudantes.

Quando falamos da necessidade de colocar em manifesto o processo que leva aos resultados externos do pensar, entendemos que é indispensável chegar à implicação do que aparece na evolução externa dos acontecimentos, descobrir a justa correspondência das condições externas e internas, etc. Ou seja, não se trata de um processo vago e geral, mas de uma concepção específica do mesmo. (RUBINSTEIN, 1963, p. 318)

No decorrer dos estudos sobre as operações racionais, evidenciamos que as obras estudadas nomeiam os processos de análise, síntese, comparação, generalização, abstração etc. com diferentes nomes; além de operações racionais, também aparecem operações mentais; atos singulares do pensamento; capacidades intelectuais; e processos mentais. Dada a variação de nomenclaturas, neste trabalho optamos por denominar de operações racionais, pois, dentre as obras utilizadas, é a forma que mais se repete, sendo as outras empregadas como sinônimos. 
Majmutov (1983) afirma que o pensamento é o processo da atividade cognitiva dos sujeitos, em que a assimilação dos conhecimentos ocorre mediante um trabalho envolvendo as operações racionais, sendo este um processo ativo. Assim, compreendemos que as operações racionais são os mecanismos internos do pensamento que medeiam os signos e símbolos na direção da apropriação dos conceitos dados socialmente, pois entendemos a mobilização das operações racionais como condição para a formação do pensamento, seja este empírico ou teórico.

0 processo do pensar é, antes de tudo, uma análise e uma síntese do que este nos proporciona; é, além disso, uma abstração e uma generalização, derivadas daqueles. As leis que regulam estes processos no âmbito das suas interinfluências constituem as leis internas básicas do pensar. (RUBINSTEIN, 1963, p. 320)

Com esse trecho de Rubinstein (1963), reafirmamos a necessidade de se investigar as particularidades que constituem o pensamento, a fim de se impulsionar a prática pedagógica, isto é, como 0 ensino pode potencializar as operações racionais as quais são condição para a formação do pensamento. A seguir, detalharemos as operações racionais: análise, síntese, comparação, generalização, sistematização, abstração e concretização.

Assim como a percepção e a sensação, o pensamento, em virtude da sua relação com o objeto, é um reflexo subjetivo da realidade objetiva. As operações racionais descritas a seguir pertencem, como descreveu Rubinstein (1974), à caracterização mais geral do processo de pensamento: "Não exclui, mas pressupõe uma multiplicidade de diferentes operações racionais (matemáticas, gramaticais etc.) com suas particularidade específicas vinculadas as particularidades do conteúdo objetivo a que se referem" (RUBINSTEIN, 1974, p. 82).

Análise e síntese são consideradas, por Smirnov e Menchinskaia (1960), operações racionais fundamentais, que tomam parte de todo pensamento e estão relacionadas e, também, condicionadas entre si. Além disso, estão presentes em todo tipo de atividade mental, ou seja, todo pensamento "[...] é uma função analítico-sintética cerebral e está constituído por distintos graus de análise síntese" (SMIRNOV; MENCHINSKAIA, 1960, p. 236). Ao constatarmos que a análise e a síntese se manifestam de distintas formas, apresentamos, no decorrer do tópico, compreensões acerca da constituição dessas operações racionais.

Apesar de a análise e a síntese serem operações diferentes, estão interligadas entre si. Com relação ao desenvolvimento psíquico, constatamos que tanto a análise como a síntese têm suas bases na atividade prática e, mesmo atingindo os níveis mais elevados do pensamento, não excluem a existência na consciência das bases perceptivas. Sobre isso, Shardakov (1977, p. 96) expõe que

0 conhecimento começa sempre com a percepção e a compreensão do conjunto, com uma síntese, já que a realidade concreta se manifesta em objetos e fenômenos integrais. Mas a primeira percepção e compreensão sintética proporciona ao indivíduo tão somente um conhecimento global e difuso, uma impressão geral dos objetos ou fenômenos; apesar dele, esta síntese inicial determina com frequência o rumo que vai seguir 0 estudo analítico dos objetos ou fenômenos. A análise inicial parte do conhecimento sintético e adquire importância somente em relação com a síntese.

Assim, é descrito por Shardakov (1977) que o conhecimento mais amplo dos objetos ou fenômenos ocorre quanto mais ampla e mais profunda for a análise a partir da síntese inicial. Desse modo, 
a síntese inicial vai se aperfeiçoando e influencia a qualidade da análise posterior, o que leva a uma nova síntese mais completa, atrelada a operações racionais de análise e síntese está a comparação.

A comparação é a operação racional que permite o estabelecimento de relações de semelhança e diferença entre os objetos e fenômenos. Esta emerge mediante a análise, assim, constitui-se como um dos elementos indispensáveis da comparação, todavia, como é afirmado por Smirnov e Menchinskaia (1960, p. 238, grifos dos autores ), "[...] a comparação não se reduz a uma análise; com ela sempre se estabelece uma relação determinada entre os objetivos ou entre as qualidades ou partes destes". Assim, ao mesmo tempo em que a comparação é uma atividade analítica, também é uma atividade sintética, pois, ao se estabelecer uma relação entre os objetos e fenômenos, inclui-se a síntese como uma parte da comparação. A operação racional de comparação possui dois elementos nucleares que são a semelhança e a diferença.

As operações racionais de classificação e sistematização aparecem como formas de distribuição dos fenômenos e objetos em grupos e subgrupos tendo como referências os elementos em comum que existem. A classificação tem como diferencial a distribuição, apresentando como critério leis gerais; já a sistematização a ordenação dos elementos em grupos e subgrupos.

Constatamos, em Smirnov e Menchinskaia (1960) e Rubinstein (1963;1974), que a generalização é a base para a formação de conceitos, os quais são os reflexos das qualidades gerais e essenciais dos fenômenos da realidade (SMIRNOV; MENCHINSKAIA, 1960). A operação racional de comparação emerge como premissa para a generalização, pois, como apontaram Smirnov e Menchinskaia (1960), somente pela comparação os indivíduos podem desvelar o que há de geral nos objetos e fenômenos da realidade objetiva, assim, agrupam-se mentalmente os elementos comparados, a fim de generalizá-los.

Sobre o processo de generalização, Davídov (1988, p. 151) afirma que o sujeito pode descobrir, mediante 0 estabelecimento de conexões alicerçadas em uma lei que determina a relação entre os fenômenos singulares, 0 "[...] caráter geral como base de uma unidade interna do sistema integral". Considerando que a generalização, como as demais operações racionais, tem suas bases nos processos perceptivos, elenca-se, nos escritos de Rubinstein (1963;1974), Shardakov (1977) e Davídov (1982;1988), a existência de níveis de generalização.

As operações de abstração e concretização são fundamentais, quando o objetivo é a generalização teórica dos conceitos. De acordo com Smirnov e Menchinskaia (1960) e Shardakov (1977), as operações de abstração e concretização estão relacionadas, pois são condições para que 0 escolar, na execução de tarefas de ensino, chegue a generalizações.

Verificamos que a operação racional de abstração tem aproximações com a operação racional de análise, visto que, de acordo com Shardakov (1977), o desenvolvimento da abstração ocorre quando os escolares devem separar e isolar objetos e fenômenos, identificando os elementos singulares, nexos e relações semelhantes e que sejam essenciais nos objetos e fenômenos e, também em decorrência disso, distinguindo o que é secundário (SHARDAKOV, 1977).

Como a abstração, a operação racional de concretização está diretamente relacionada com a generalização, pois, enquanto a abstração consiste em se separar e isolar o que é comum (e também o que não é), cabe à concretização ilustrar, ou seja, exemplificar os conceitos, leis e regras por meio de procedimentos visuais, acontecimentos isolados, experimentos de laboratório etc. (SHARDAKOV, 1977).

A concretização nos aproxima ao que percebemos pela experiência sensorial, ao que é mais objetivo e mais conhecido. Isto precisamente reside sua importância essencial 
para compreender geral. Isto é baseado na ajuda que oferecem os exemplos e as ilustrações do geral. 0 aluno sempre compreende melhor explicações do professor quando este mostra exemplos e casos concretos nos que se manifesta aquilo sobre o que tem chamado em termos gerais. (SMIRNOV; MENCHINSKAIA, 1960, p. 241).

Shardakov (1977) cita os estudos de Rubinstein (1963) ao expor o conceito de concretização relacionado com as disciplinas de matemática e física, pois o conhecimento advindo destas matérias direciona a resolução de problemas derivados da mesma área. Entretanto 0 autor adverte que essa operação racional também se manifesta na elaboração de fórmulas para a solução desses problemas, assim, emerge um modo de ação geral concretizado que permite a generalização dos problemas expostos.

Smirnov e Menchinsckaia (1960) descrevem que o processo das operações racionais se destaca no movimento de compreensão dos conceitos. Em meio ao movimento das operações racionais, decorrente dos processos de análise, síntese, comparação e outros, há, por meio de um ensino adequadamente organizado, a descoberta do que é essencial nos fenômenos e objetos da realidade objetiva. Destacamos que o percurso das operações racionais na direção da formação do pensamento teórico é posto em movimento em decorrência de um problema de natureza, também teórica, isto é, uma pergunta que mobiliza as operações racionais dos estudantes para a apropriação de conceitos científicos. Com isso, o processo das operações racionais tem começo, meio e fim, sendo assim, uma direção que resulta em determinado tipo de generalização e compreensão a depender a organização do ensino.

Em busca de expor os dados empíricos o processo racional do pensamento, no próximo tópico apresentamos duas cenas do episódio ${ }^{5}$ que foi extraído da dissertação de Santos (2020) que realizou observações em aulas de matemática em um terceiro ano de escolarização, a fim de identificar a direção que a organização do ensino, portanto, as tarefas como também o encaminhamento metodológico influi nas operações racionais e na direção do desenvolvimento do pensamento, seja ele empírico ou teórico.

\section{AS OPERAÇÕES RACIONAIS: 0 MOVIMENTO DO CONHECIDO AO DESCONHECIDO}

Nos tópicos anteriores, descrevemos que o pensamento vai do conhecido ao desconhecido, tal proposição é elencada nos trabalhos de Rubinstein (1973). Nomeamos o episódio na dissertação de "necessidade de conhecimento pelas situações introdutórias", que, em nossa concepção, evidencia 0 movimento das operações racionais do conhecido ao desconhecido gerado pelas tarefas escolares. Consideramos que as situações introdutórias, das quais a docente faz uso, como reveladoras da necessidade de aprofundamento dos estudos acerca desse movimento.

Nesse sentido, o que estamos denominando de situações introdutórias? São aquelas que ocorreram no momento inicial da aula, pelas quais a docente optou, por meio de um problema ou explicação oral, abordar o tema da aula, de modo que essa abordagem crie nos alunos a necessidade de estudo ou a verificação das manifestações desse conteúdo em problemas práticos. De modo geral, em todas as tarefas realizadas pelos estudantes, havia uma introdução, fosse de caráter problematizador ou explicativo. Contudo, das aulas e tarefas observadas, retiramos duas para explicitarmos 0 fenômeno do conhecido ao desconhecido. Também constatamos que as demais aulas eram iniciadas com correções de exercícios (sem uma explicação mais aprofundada de caráter introdutório), os

5 Moraes (2008, p. 136, grifos da autora) afirma que os isolados/unidade de análise "[...] são compostos por episódios que são classes de fatos de explicitam empiricamente o fenômeno". 
quais consideramos insuficientes para corroborar o conteúdo que desejamos discutir neste episódio, ou seja, movimento do conhecido ao desconhecido mediante um problema a ser resolvido.

Em certa medida, essas situações introdutórias colocaram 0 escolar diante de algo que pode ser desconhecido.

Em consequência, é necessário um conhecimento mais profundo do mundo, e descobrindo novos processos, propriedades e inter-relações das coisas. 0 pensamento é necessário porque, no transcurso da vida e atividade, cada indivíduo se defronta com certas propriedades novas dos objetos que antes Ihe eram desconhecidas. Os conhecimentos anteriores resultam então insuficientes. (PETROVSKI, 1980, p. 292)

Assim, para este episódio, apresentamos duas cenas que inserem o escolar diante de um novo conteúdo a ser estudado. A primeira cena é decorrente do trabalho com o conceito de ordem, ao qual nomeamos de "Conceito de ordem"; a segunda cena diz respeito às implicações decorrentes do estudo da história da multiplicação, pela qual surgiu a necessidade, pelos escolares, de abordar 0 conceito de inteiro negativo, contudo não estava programado esse trabalho pela professora. Denominamos essa cena de "Ué, mas como, se a gente está em 2019?".

\section{Conceito de ordem}

No intuito de iniciar/retomar 0 trabalho com o conceito de ordem, a docente realizou duas situações introdutórias que estavam diretamente relacionadas. Na primeira, ela recorreu aos dias da semana e os registra na lousa:

Profa.: Nós começamos a escrever números ordinais para os dias da semana. Aí a professora falou o que para vocês? Olha, segunda-feira eu escrevo com qual número? Turma: Dois.

Profa.: Isso, porque é segunda-feira [registra no quadro o " 20 -feira"]. Terça-feira eu coloco qual dia?

Turma: Três.

Profa.: Porque é o terceiro dia. E o quatro é o quê?

Turma: Quarta-feira.

Temos, pois, que as respostas dadas pelos estudantes derivam da comparação permeada pela análise e síntese. A comparação ocorre, segundo Rubinstein (1973), do confronto entre as coisas e os fenômenos e, também, das qualidades que estes possuem, resultando do reconhecimento de sua identidade e diferença. Quais são as qualidades a que nos referimos? As que levam à semelhança do número "dois" e da manifestação deste como número ordinal "segundo". Tendo como referência os conhecimentos que os escolares já possuem, estes chegam à síntese de que os dias da semana têm uma ordem em sua nomenclatura.

Consideramos esse tipo de comparação restritiva se 0 conceito não for aprofundado e ampliado, visto que não temos o "primeiro-feira" ou "sétima-feira". Desse modo, tal generalização, como resultado da comparação, em meio à análise e à síntese do conceito, se direcionam a uma generalização empírica do referido conceito. Rubinstein (1963) define a comparação como a forma concreta em que a síntese e a análise se direcionam a outra operação mental, a generalização na 
qualidade empírica, isto é, trata-se de um ponto inicial do conhecimento, mas não deve ser restringido ao mesmo.

A comparação pura e exclusiva do conceito de ordem com os dias da semana leva a uma generalização empírica desse conceito, pois, mesmo que esta operação se configura como um modo de uso deste conceito, não revelam um modo geral 0 conceito de ordem. A cena a qual nos propomos a expor não termina com essa constatação. Decorrente da tarefa acima mencionada, a professora solicita que uma fileira de alunos vá até a frente da sala e que permaneça na ordem em que se sentam na fileira.

Profa.: Vou fazer uma pergunta inteligente. Qual é ordem dessa aqui, é qual? [aponta para a aluna].

Turma: Primeira.

Profa:: E essa aqui?

Turma: Segunda.

Profa.: E essa aqui?

Turma: Terceira.

Profa.: E essa aqui?

Turma: Quarta.

Profa.: E essa?

Turma: Quinta.

Profa.: Lembram do dia da semana como facilitou? Olha só, agora vocês vão falar 0 nome, porque todo mudo sabe o nome de todo mundo. Nessa ordem que nós estamos, nós estamos em uma fila, em uma ordem. Quem é o primeiro da fila?

Turma: CA.

Profa.: Quem é o terceiro da fila?

Turma: RA.

Profa.: Quem é o último da fila?

Turma: NA.

Profa.: Quem é a quarta da fila?

Turma: MA.

Temos, nesse trecho, o que pode ser uma tarefa que direcione para a apropriação do conceito, pois, mesmo permanecendo no aspecto discursivo e relacionada ao objeto, a tarefa explora a essência do conceito de ordem, que está na posição em que o sujeito, objeto ou fenômeno se localiza. Essa proposição de abordagem introdutória avança, pois, em um primeiro momento, a docente recita, junto com os escolares, as posições, entretanto, em seguida, complexificação a tarefa exigindo que os alunos definam as posições em que os estudantes dispostos em fila se encontram.

Profa.: 0 que tem de diferente?

PE: A AN estava aqui e foi para lá.

Profa.: Mas a AN estava em qual lugar?

PE: Ela estava em terceiro.

Profa.: Agora ela está em que lugar?

PE: Segundo.

Profa.: E o que mais que aconteceu?

PE: O NT estava em segundo e foi para primeiro.

Profa:: Muito bem, olha só. Eu vou deixar mais comprida a fila. Vem a segunda 
fila na ordem que vocês estão. Olha só, AM conta para mim em número ordinal a quantidade de pessoas que eu tenho. [A AM começa a contar]. Vamos, mais alto eu quero ouvir.

AM: Segundo, Terceiro, Quarto.

Profa.: Não, começa pelo primeiro. Vem aqui e mostra para eles quem é o primeiro, 0 segundo e o terceiro. Vamos lá AM.

AM: Segundo, terceiro... [apontando para os alunos da fila]

Profa.: Mas como é segundo se ele é o primeiro? Vamos lá ele está ali na frente, ele é o? AM: Segundo.

Profa:: Não, começa do primeiro, dia da semana que começa na segunda, vamos lá. EM: 0 R0 é o Primeiro, A RA é a Segunda, 0 JO o Terceiro; A MA é a Quarta; 0 EN é o Quinto; A LA é a Sexta; 0 DA é o Sétimo; A LI é o Oitavo; 0 LE é o Nono e a EV é a Décima.

Temos que considerar e valorizar o trabalho da docente em relação à complexificação da tarefa, isto é, quando solicita que os escolares identifiquem as posições utilizando a linguagem ordinal do número. Além de disso, vemos, no início do trecho (fala de PE), que o escolar realiza o movimento de análise e síntese tendo como referência a comparação de duas fileiras com apoio da memória, sendo a primeira a ordem em que os estudantes estavam sentados em relação à segunda que é a ordem alterada pela professora.

Constatamos que há outra complexificação da tarefa, em que a docente aumenta a quantidade de pessoas na fila e em seguida solicita que a aluna "conte" em número ordinal os estudantes que estavam enfileirados. Há, porém, um erro da aluna, que é resultante de uma generalização empírica sobre 0 conceito de ordem. Retomando os trechos anteriores, vimos que a docente inicia a explicação do conceito de ordem pelos dias da semana. Contudo, qual é o primeiro dia da semana que nomeamos e que tem em sua nomenclatura o número em sua face ordinal? A segunda-feira.

Nossa hipótese torna-se plausível à medida que vemos a estudante iniciando mais de uma vez a contagem dos números ordinais, nomeando o primeiro como segundo. Diante das intervenções da docente, a aluna corrige e identifica quem é o primeiro, o segundo, o terceiro e assim sucessivamente.

Desse modo, consideramos que a segunda tarefa avança qualitativamente as possibilidades de generalização do conceito de ordem, pois os processos racionais (análise, síntese etc.) têm apoio no concreto palpável, ou seja, no campo perceptível, e, com base nos estudos, vimos que os processos perceptíveis são a base do pensamento. Não podemos afirmar, contudo, que a primeira tarefa não tem relação com o conceito de ordem, pois, se os dias da semana estão posicionados, é então possível reconhecê-los em uma ordem. Porém, iniciar o conceito de ordem comparando os dias da semana com a contagem ordinal é, em nossa concepção, levar os processos racionais em direção à generalização empírica do conceito de ordem.

\section{Ué, mas a gente não está em 2019?}

0 título da cena é a fala de um dos alunos que acreditamos ser reveladora do que nos propomos a discutir nesse episódio, isto é, a possibilidade de identificar as operações racionais nas situações introdutórias feitas pela docente, uma vez que há a necessidade de mover-se do conhecido ao desconhecido.

Nas aulas anteriores a essa cena, a professora abordou o conceito de multiplicação e utilizou a tabuada como manifestação deste conceito. No decorrer deste trabalho, os estudantes indagaram 
a professora sobre a origem da tabuada. A indagação se justifica, pois os estudantes tiveram aulas com estagiárias do curso de Pedagogia, em que elas abordaram a história dos sistemas de medidas (palmo, polegar, braça e centímetro) com os estudantes, e tal trabalho desdobrou-se na curiosidade de se conhecer a história da tabuada.

0 movimento do conhecido ao desconhecido pode ser identificado nessa passagem, contudo, se permanecêssemos nesse trecho com a afirmação de que a necessidade do conhecido ao desconhecido vem do querer mais explicações da docente, isso seria um equívoco. A professora, atendendo ao pedido dos estudantes, inicia a aula abordando a história da tabuada, para isso realizou anteriormente uma busca na internet e a organizou em formato de slides. A professora atribui a Pitágoras a criação da tabuada e, a partir disso, conta a história deste filósofo e eminente matemático.

Profa.: Então, no começo ele não era matemático, ele gostava de estudar o porquê aconteciam as coisas. Lembra que as meninas vieram aqui e contaram a história do carneirinho? Que primeiro começou a contar com gravetos e depois com pedras? E as coisas ficaram difíceis e eles começaram a fazer o sistema de numeração decimal. E aí Pitágoras, querendo que as coisas fossem mais rápidas, organizou uma forma da gente fazer as coisas mais rápidas. E aí que ele criou a tabuada.

\section{DA: Mas e 0 ábaco?}

Profa.: Ele é também para fazer as contas mais rápidas.

No início da explicação, a docente fez comparou a origem da tabuada com a história da criação do sistema de numeração decimal ${ }^{6}$ que, conforme relatado da professora, foi desenvolvida por alunas do Programa Institucional de Bolsas de Iniciação à Docência (PIBID), do curso de Pedagogia. A exposição da docente afirma que a criação dos instrumentos deriva da necessidade de se realizar cálculos com mais velocidade. Contudo, um aluno (DA) questiona sobre 0 ábaco. Consideramos que essa indagação feita pelo aluno vai em direção ao que apontaram Smirnov e Menchinskaia (1960) que a comparação ocorre segundo um aspecto ou qualidade, isto é, por uma particularidade. Além disso, podemos inferir que o escolar, também, ao comparar, classifica o instrumento, e, nos estudos de Shardakov (1977), identificamos como o segundo nível de classificação, em que "[...] os escolares relacionam o objeto isolado com o correspondente conceito geral, baseando-se em suas características idênticas, sobretudo de caráter utilitário ou funcional" (SHARDAKOV, 1977, p. 286).

Assim, 0 estudante sintetiza uma questão, que é resultado da comparação à utilidade de dois instrumentos. Dando continuidade à cena, a docente se encaminha para expor a história da tabuada.

Profa.: Mas aí, tem uma história que eu encontrei na internet que eu não lembrava muito bem, que é meio triste. Tabuada vem da palavra tábua. Então é assim ó, a primeira tabuada que ele fez [Pitágoras] tem seu lado positivo. Como na época do Pitágoras não tinha papel, ele fez em madeira, porque ele nasceu há mais de 3.000 anos atrás.

\section{LE: Ué, mas como, se a gente está em 2019?}

A questão realizada pelo aluno é reveladora e põe em evidência o que nos propomos a evidenciar nesse episódio, em que as operações racionais são mobilizadas por meio da necessidade de se avançar do conhecido ao desconhecido. Observamos que a docente não tinha, em seus objetivos da

6 MOURA, M. O. (Coord.) Organizando a contagem em sistemas. Programa de Formação Continuada. Fundação de Apoio à Faculdade de Educação/USP: São Paulo, 2003. 
aula, o ensino dos números pertencentes ao conjunto dos números inteiros ${ }^{7}$. Entretanto, a situação introdutória por ela organizada exigiu este conceito, até porque 0 controle das diferentes grandezas não se restringe ao conjunto dos números naturais.

Nessa situação, evidenciamos que 0 aluno realiza o movimento de análise, em que desmembra mentalmente as informações ditas pela docente. Porém, perceber os "3.000 anos atrás" entra em conflito, o que é verbalizado em uma síntese a qual é resultado de uma comparação das informações que antes foram desmembradas. Rubinstein (1963) afirma que, "Por sua própria essência, 0 problema é sempre uma formulação verbal e constitui um testemunho vivo da unidade formada pelo pensamento e a linguagem" (RUBINSTEIN, 1963, p. 368).

0 fato é que a necessidade de se avançar do conhecido ao desconhecido estava ali, foi verbalizada e, podemos dizer, sem ter sido planejada pela professora. Questionamos: como a docente procedeu com a indagação? Considerando os pressupostos teóricos já elencados neste estudo, postulamos que somente um ensino adequadamente organizado possibilita o máximo desenvolvimento das funções psíquicas superiores. Assim, diante de uma questão que emerge como necessidade de apropriação de um novo conceito, a docente interage com os escolares, de modo que eles compreendam 0 que está sendo explicado.

Profa.: É assim, quando existiam os tempos antigos, o tempo foi marcado em números e anos com o nascimento de Cristo. Então, existe aqui o "a. C." e "d. C". Isso são siglas, a. C quer dizer antes de Cristo [semelhante a um plano cartesiano]. Então, os anos antes de Cristo vêm para cá [lado esquerdo do quadro].

LE: E o d. C. é depois de Cristo. [professora registra "d. C." depois de Cristo no lado direito do quadro].

Profa.: Existiam os anos normais. Ano 1, 2, 3, 100, 200, 300, 500.

AR: Nossa, tinha 0 ano 1.000 !

Profa.: Quando Cristo nasceu, tinha todos os anos antes, 2.000 e 3.000 anos antes. Mas, quando Cristo nasceu, zeraram o ano e começaram a contagem novamente. Até chegar a 2019.

DA: Então é tipo como se o mundo tivesse 4.000 anos?

Profa.: É para gente entender, quando Cristo nasceu, começaram a contagem novamente. Então, se a gente for parar para pensar, a humanidade tem só 2.019 anos? Não. Ela tem muito mais.

Temos, nesse trecho, a manifestação de três sínteses que se complementam, o que reforça a afirmação de que o movimento das operações racionais não é único na resolução de um problema, mas que o movimento, por exemplo, de comparação, análise, síntese é executado diversas vezes. A primeira é complemento do que a professora estava afirmando, isto é, uma síntese resultante da comparação de um conhecimento que o estudante já possui. Não necessariamente que 0 escolar domine a periodização antes de Cristo e depois de Cristo, contudo é perceptível que ele domina as relações temporais de antes e depois, até porque é possibilitada visualmente ao estudante a posição onde se encontram 0 antes e 0 depois. Rubinstein (1973) afirma que as análises e sínteses, antes de atingirem um nível teórico, primeiramente, há que se efetuarem como análises e sínteses práticas, portanto, visualizar e comparar os elementos são modos de se atingir o nível teórico de pensamento.

A segunda e a terceira sínteses são próximas, pois, em nossa concepção, os escolares as

7 Permanece a ideia dos números naturais e passa-se a englobar os números negativos inteiros. (POMMER, 2010). Exemplo: $\{\ldots-.-3,-2,-1,0,1,2,3 \ldots\}$. 
realizam comparando as quantidades em relação à sua disposição na reta traçada pela docente - a segunda deriva de sua sequência e a terceira, de uma possível junção entre todas as quantidades ali apresentadas. 0 cálculo não resultaria em "4.000", no entanto é possível verificar a tentativa do estudante de estimar quantos anos o mundo tem.

Nesse sentido, constatamos que o pensamento se mobiliza mediante um novo problema. No episódio, destacamos as situações introdutórias que, em nossa opinião, demandaram do pensamento dos estudantes a necessidade de caminharem do conhecido ao desconhecido mediante a mobilização das operações racionais, isto é, os estudantes, por meio de seus processos racionais, concluíram que os conhecimentos que possuíam sobre determinados conceitos eram insuficientes.

Nesse episódio que é composto por duas cenas, destacamos que o movimento do conhecido ao desconhecido é mobilizado por uma situação introdutória. A mobilização do pensamento em direção ao desconhecido é condição para o desenvolvimento qualitativo das operações racionais. Assim, postulamos que as situações introdutórias exigem, por meio da mobilização das operações racionais, a necessidade de ir do conhecido ao desconhecido. Portanto, a direção das tarefas escolares deve ser criar a necessidade de se ir em direção ao desconhecido, quando se tem como objetivo a aprendizagem de conceitos sistematizados e significativos para os estudantes.

\section{CONSIDERAÇÕES FINAIS}

Neste trabalho nos propomos a expor parte dos resultados de uma pesquisa de mestrado que teve como objetivo investigar 0 as operações racionais de estudantes do terceiro ano de escolarização mediante a execução das tarefas escolares de matemática. Partimos do pressuposto de que as potencialidades da educação escolar, em específico, da organização do ensino de matemática. Em meio a esta exposição, pontuamos quais são as contribuições do ensino para o desenvolvimento humano, que decorre das aprendizagens.

A escola como espaço de aprendizagem deve ser o lugar em que os sujeitos agem produzindo e apropriando de significações para dar sentido pessoal à vida, tendo como referência um coletivo empenhado em um projeto humano. Seu fim específico é organizar o ensino porque acredita que essa seria a forma mais objetiva de se dar acesso à cultura. (MOURA; ARAÚJO, 2018, p. 203)

No episódio selecionado para esse texto, buscamos expor o movimento do conhecido ao desconhecido em relação com as operações racionais, pois, nos estudos da Teoria Histórico-Cultural, postula-se que o pensamento deve ir do conhecido ao desconhecido mediante a existência de motivos para 0 estudo. Assim, constatamos o que engendra essa possibilidade de o pensamento avançar são as operações racionais que medeiam os signos e símbolos dados socialmente, portanto, o pensamento que tem origem nas sensações e percepções só ganha condição de pensamento em razão das operações racionais. Nas cenas utilizadas para explicitar o fenômeno, verificamos que as situações introdutórias são vias possíveis trabalho do conhecido até 0 desconhecido, e, nesse primeiro episódio, recebem destaque as operações racionais de análise, síntese, comparação e classificação.

Em meio a esse estudo sobre a organização do ensino, consideramos que esta deve ser sempre pensada com 0 objetivo de que os estudantes formem o pensamento teórico. Um fator fundamental que não pode ser desconsiderado é a atuação da professora, a qual atuou buscando agir conforme sua função na prática pedagógica. Inferimos que houve planejamento das aulas visando que os estudantes se apropriassem dos conceitos, ela se organizou para sanar dúvidas que surgiram mediante o trabalho com estudantes e, também, avaliou suas ações. Assim, o ensino foi organizado pensando 
nos escolares, contudo existem práticas e hábitos cristalizados no processo educativo que inviabilizam a mudança de qualidade das operações racionais e, com isso, a formação do pensamento teórico.

Isso está relacionado com muitos fatores que extrapolam o agir dessa docente e nos coloca a pensar sobre as políticas públicas para a educação, em que a formação de professores e o próprio trabalho deste profissional não são valorizados. A formação tem que ser inerente à ação docente, uma efetiva formação teórica-metodológica que envolva a concepção homem, sociedade, desenvolvimento humano e encaminhamentos metodológicos para o ensino e a aprendizagem.

\section{REFERÊNCIAS}

ARAÚJO, E. S; MORAES, S. P. G. Dos princípios da pesquisa em Educação como Atividade. In: MOURA, M. 0 (org). Educação Escolar e pesquisa na Teoria Histórico-Cultural. - São Paulo: Edições Loyola, 2017.

ASSUMPÇÃO, M. P. Que tipo de pensamento a escola tem desenvolvido nos educandos? Uma análise das tarefas escolares do eixo números e operações. 143f. Dissertação (Mestrado em Educação) - Universidade Estadual de Maringá, 2018.

CARAÇA. B. J. Conceitos Fundamentais da Matemática. Lisboa: Livraria Sá da Costa Editora. 1951.

CHAIKLIN, S. A zona de desenvolvimento próximo na análise de Vigotski sobre aprendizagem e ensino. Traduzido por Juliana Campregher Pasqualini. Psicologia em Estudo, Maringá, PR, v. 16, n. 4, p. 659-675, out./dez. 2011.

DAVÍDOV, V. V. Análisis de los principios didácticos de la escuela tradicional y posibles principios de enseñanza en el futuro próximo. In: SHUARE, M. La psicologia evolutiva y pedagógica en la URSS: Antologia. Moscou: Progreso, 1987. p. 143-142.

DAVÍDOV, V. V. La enseñanza escolar y el desarrollo psíquico: investigación psicológica teórica y experimental. Moscou: Editorial Progreso, 1988.

DAVIDOV. V. V. 0 que é a atividade de estudo. Revista <<Escola inicial>>. N07, 1999.

DAVÝDOV, V. V. Tipos de generalización enl aenseñanza. Havana: Pueblo y Educación, 1982.

FERREIRA, M. P. As bases para a organização do ensino de geometria: uma análise sobre as tarefas escolares. 177f. Dissertação (Mestrado em Educação) - Universidade Estadual de Maringá, 2017.

LACANALLO, L. F. 0 jogo no ensino da matemática: contribuições para o desenvolvimento do pensamento teórico. 218 f. Tese (Doutorado em Educação) - Universidade Estadual de Maringá, 2011.

LACANALLO, L. F. Vamos jogar? Jogo, princípios e possibilidades para o ensino de matemática. 1. Ed. Curitiba: Appris, 2018.

LEONTIEV, A. N. Actividad, conciencia, personalidad. Habana: Editorial pueblo y educacion, 1984.

MAJMUTOV, M. I. La Enseñanza Problémica. Habana: Pueblo y Revolución. 1983. 
MARTINS, L. M. Desenvolvimento do pensamento e educação escolar: etapas de formação de conceitos à luz de Leontiev e Vigotski. Fórum linguístico, Florianópolis, v. 13, n. 4, 2016. p. 1572-1586.

MARTINS, L. M. 0 desenvolvimento do psiquismo e a educação escolar: contribuições à luz da psicologia histórico cultural e da pedagogia histórico-crítica. 1ª. São Paulo: Autores Associados. 2013.

MARTINS, L. M. Desenvolvimento do pensamento e educação escolar: etapas de formação de conceitos à luz de Leontiev e Vigotski. Fórum linguístico, Florianópolis, v. 13, n. 4, 2016. p. 1572-1586.

MARTINS, L. M. 0 desenvolvimento do psiquismo e a educação escolar: contribuições à luz da psicologia histórico cultural e da pedagogia histórico-crítica. 1ª São Paulo: Autores Associados. 2013.

MORAES, S. P. G. Avaliação do processo de ensino e aprendizagem em Matemática: contribuições da Teoria Histórico-Cultural. 2008. Tese (Doutorado em Educação) - Faculdade de Educação, Universidade de São Paulo, São Paulo, 2008.

MORAES, S. P. G.; MOURA, M. O. Avaliação do Processo de Ensino e Aprendizagem em Matemática: contribuições da teoria histórico-cultural. Bolema: boletim de educação matemática, Rio Claro, SP, v. 22, n. 33, p. 97-116, 2009.

MOURA, M. 0., "Educar con las matemáticas: saber específico y saber pedagógico", Revista Educación y Pedagogía, Medellín, Universidad de Antioquia, Facultad de Educación, vol. 23, núm. 59, enero-abril, 2011, pp. 47-57.

MOURA, M. 0.; ARAUJO, E. S. A Atividade Orientadora de Ensino como Mediação. In: BEATÓN, G. A; SOUZA, M. P. R; BARROCO; S. M. S; BRASILEIRO, T. S. A. (Orgs.) Temas escolhidos na Psicologia Histórico-cultural: interfaces Brasil - Cuba. 2018, p. 193- 213.

MOURA, M.O. Matemática na infância. In: MIGUEIS, M. R.; AZEVEDO, M.G. Educação matemática na infância: abordagens e desafios. Serzedo, Vila Nova de Gaia: Gaialivro, 2007. p. 39-64.

PETROVSKI, A. Psicología General: Manual didáctico para los Institutos de Pedagogía. 3. ed. Moscú: Editorial Progreso, 1980.

POMMER, W. M. A construção de significados dos números irracionais no ensino básico: uma proposta de abordagem envolvendo os eixos constituintes dos números reais. Tese (Doutorado em Educação), Universidade de São Paulo, 2010.

RUBINSTEIN, S. L. El desarrollo de la psicologia: princípios y métodos. Ediciones pueblos unidos: Montevideo. 1974.

RUBINSTEIN, S. L. El ser y la consciencia y El pensamiento y los caminos de su investigación. Editora Grijalbo, México, 1963.

RUBINSTEIN, S. L. Princípios de Psicologia Geral. IV, 4. Lisboa: Editorial Estampa. 1973.

RUBINSTEIN, S. L. SOKOLOV, A. N. Objeto, problemas e métodos de la psicologia. In: SMIRNOV A.A., RUBINSTEIN S.L. y varios. Psicología. Tratados y Manuales Grijalbo 1960, p. 13-36.

SANTOS, E. A. Tarefas escolares e as operações racionais: um estudo sobre a organização do ensino de matemática. 153 f. Dissertação (Mestrado em Educação) - Universidade Estadual de Maringá, 2020. 
SFORNI, M. S. F. Aprendizagem Conceitual e Organização do Ensino: Contribuição da Teoria da Atividade. 1. ed. Araraquara: JM Editora, 2004.

SFORNI, M. S. F. Ensino, aprendizagem e desenvolvimento: contribuições da Teoria da Atividade. In: Psicologia dos processos de Desenvolvimento Humano: Cultura e Educação (Livro Unb), 2016.

SFORNI, M. S. F. Interação entre Didática e Teoria Histórico-Cultural. Educ. Real. [online]. 2015, v. 40, n. 2, 2015, p. 375-397.

SHARDAKOV. M. N. Desarrollo del pensamiento en el escolar. 1977.

SMIRNOV, A. A; MENCHINSKAIA, N. A. El pensamento. In: SMIRNOV A. A., RUBINSTEIN S. L. y varios. Psicología. Tratados y Manuales Grijalbo 1960, p. 232-275.

TALIZINA, N. F. La formación de los conceptos matemáticos. In: TALIZINA, N. F. (Org.) La formacion de las habilidades del pensamiento matemático. Universidade Autónoma de San Luis Potosí - México, 2001.

VIGOTSKII, L. S. Aprendizagem e desenvolvimento intelectual na idade escolar. In: VIGOTSKII, L. S; LURIA, A. R; LEONTIEV, A. N. Linguagem, Desenvolvimento e Aprendizagem. São Paulo: Ícone, 1988.

VIGOTSKY, L. S. Obras Escogidas. Tomo II. Visor. España, 1991.

VIGOTSKY, L. S. Obras Escogidas. Tomo III. Visor. España, 2000.

RECEBIDO EM: 30 jun. 2020

CONCLUÍDO EM: 13 set. 2020 